\title{
MENTAL PREPARATION STRATEGIES AND FIREFIGHTER'S PERFORMANCE UNDER STRESS
}

\author{
NICKI MARQUARDT, LISA KRÄMER \& VERENA SCHÜRMANN \\ Rhine-Waal University of Applied Science, Kamp-Lintfort, Germany.
}

\begin{abstract}
Firefighters have to perform in high demanding environments, which require the ability to cope with stress. Research has shown that performance as well as stress reduction is affected by mental preparation strategies such visual imagery, activation, self-confidence, attentional control, relaxation, goal setting and self-talk. The outcome of mental preparation strategies is a psychological state called 'mental readiness'. Mental readiness emerged from sport psychology and was found to be important for performance improvements of top athletes. However, until now mental readiness has never been used to predict firefighter performance. Thus, the purpose of this study is to examine the relationship between mental readiness dimensions and perceived stress, success and task performance of firefighters. A sample of 68 firefighters was surveyed. The mental readiness dimensions as well as performance and stress issues were measured with the Mental Readiness Scale (MRS). Correlations and multiple regression analyses showed mixed results. Some scales like self-talk and goal setting did not significantly correlate with performance, success or stress of firefighters, whereas other sub scales such as visual imagery, activation and attentional control showed medium to large effects. The results reveal that firefighters benefit differently from the specific mental preparation strategies. Some strategies help firefighters to cope with stress. Other strategies seem to improve task performance and success. The results can be used to design evidence-based mental training programs to improve firefighter's performance and stress reduction.
\end{abstract}

Keywords: attentional control, firefighters, imagery, mental preparation, mental readiness, stress, task performance.

\section{INTRODUCTION}

The task environment of firefighters is physically demanding [1] due to several circumstances: performance in a dangerous chaotic environment in which they have to execute considerable, time-pressured muscle work and knowing that civilians they are responsible for are in danger [2, 3, 4]. In 2010, the National Fire Protection Association (NFPA) reported 71.875 firefighter line-of-duty injuries, which emphasizes the high demands this position entails [5].

A psychological approach to enhance firefighter's performance under stress is to improve the mental state of them when they are in operation by mental preparation.

\subsection{Mental Preparation}

The scope of mental preparation encompasses several cognitive and emotional techniques facing the goal to achieve higher performance by including attention focusing, positive imagery, psyching-up strategies, self-efficacy statements and relaxation [6]. Mental Preparation strategies are widely used in the field of sports and research has already shown their effectiveness on athlete's performance [7].

\subsection{Mental Readiness}

The concept 'Mental Readiness' also emerged in the field of sports psychology and describes an optimal mental state to perform. According to Orlick and Partington mental readiness 
'(...) derived from a number of learned mental skills that must be continually practiced and refined for an athlete to perform (...) on a consistent basis' [8]. Therefore, mental readiness can be seen as a result of mental preparation to achieve peak performance. In the 1980s Orlick interviewed world-class athletes and identified several mental readiness elements that contribute to sports excellence and high-performance. These elements involve constructs such as attentional control, goal-setting, activation, relaxation, self-confidence, self-talk and imagery $[8,9]$.

\subsubsection{Attentional Control}

Attentional control is the ability to concentrate and focus on a particular task resisting distraction [10]. A great variety of studies confirm a relationship between attentional control and increasing performance in the field of sports [11, 12, 13], but also in music [14, 15], motor skills [16], sleep-deprivation [17] and medicine [18]. Distraction control, which belongs to attentional control, can be described as the ability to control or to ignore the processing of distracting information [19]. Several studies identified distraction control as one of the most successful strategies to perform at a higher level $[8,20]$. Moreover, Church, Rumbold and Sandars (2017) developed a model of pre-performance routine to build up performance by transferring insights from the field of sport psychology to medicine, which also includes distraction control [21].

Both, attentional control as well as distraction control might be important for firefighters, in order to stay focused in a distraction-filled environment as well as to prioritize tasks wisely. Especially such mental pre-performance strategies might be helpful to achieve optimal performance and to reduce stress.

\subsubsection{Goal Setting}

In 1990, Locke and Latham developed a motivational theory of goal setting, which suggested that people will be motivated to achieve their goals and how these goals will influence the performance [22]. A goal, within this theory, is an aim or object of an action [23]. The core assumption of the theory is that higher performance can be achieved by challenging and besides, specific goals instead of vague goals [22]. Various studies support these assumptions, e.g. in the field of job performance [24] or education [25]. The important role of goal setting especially in context of performance was already pointed out by Orlick and Partington, who stated high-class athletes use goal setting as one of the elements of success [8].

Based on these findings we assume that both specific and realistic goals are key components to perform on a higher level and to solve critical situations in the context of firefighters.

\subsubsection{Activation}

The concepts of arousal and activation refer to aspects of performance [26] and several studies suggest a separation of both terms [e.g. 26, 27]. Activation can be defined as a strategy to mobilise arousal for a particular task, whereas arousal refers to the energetic state at this moment [27]. According to this definition, activation can be seen more as a planned action in general.

The important role of arousal management was already illustrated by the Inverted $U$ Hypothesis by Hebb [28], which highlights the link between arousal and performance. It is of importance that both underarousal as well as overarousal do not increase performance [28]. Hence, mental strategies were used to improve performance [29]. Preparatory arousal is a mental preparation strategy, which can be defined as preparing oneself for a maximum 
performance by getting aroused or pumped-up [30] for instance by producing specific emotions [31] or other specific techniques like fast breathing [32].

Transferring these outcome to the field of firefighters, activation strategies might reduce the perceived stress level, enhance performance and lead to success. However, these preparation strategies should not lead to overarousal, otherwise firefighters might overestimate their own strength.

\subsubsection{Relaxation}

Relaxation can be defined as a coping strategy, which is used to manage physically, psychologically and emotionally demanding situations [33]. Furthermore, relaxation is part of the arousal management, which was already introduced in connection to activation. Hence, it is necessary to find the ideal level of arousal to strengthen performance otherwise it will decrease due to overarousal or underarousal [28]. Literature distinguishes between two types of relaxation: physical and mental. The former describes a regulation of physical parameters, for instance breathing [34] whereas mental relaxation is attained by regulation of thinking in form of mediation [35].

A recent study (2018) used relaxation therapy as one of three psychological intervention programs to assess the effects on mental stress and coping style. This relaxation therapy encompassed: progressive muscle relaxation (PMR), mediation, though guidance, deep breathing and massage [36]. Results revealed that participants in the intervention program improved mental state, reduced negative coping style and showed lower levels of anxiety [36]. Moreover, Orlick and Partington identified breathing techniques and PMR as two of the most efficient strategies to increase performance [8]. Besides these two strategies, relaxation in general is investigated in different fields like sports [8, 37], medicine [36] and human performance [38], which proved a relationship between relaxation and performance.

Due to the presented results, we assume that relaxation could help firefighters to improve performance in a stressful situation, which in turn might lead to success.

\subsubsection{Self-confidence}

In general, self-confidence is defined as 'the belief that one can successfully execute a specific activity' [39]. Besides the term self-confidence, self-efficacy is also used to describe the perceived capability to gain a certain level of performance [39]. According to Bandura self-efficacy is the personal judgment of one's capabilities to organize and execute courses of action required to reach intended types of performances [40]. Therefore, self-efficacy can be seen as an assessment of possible achievement due to personal skills [40].

Literature has shown a relationship between self-confidence and performance in the field of sport [41], music [15] and medicine [18]. However, some studies also revealed a negative relationship between self-confidence and performance [42,43]. This might be possible due to a risk-taking behaviour as a result of high confidence [44].

In the field of firefighters, self-confidence might play an important role, because in extreme situations firefighters should believe in their own abilities. If so, high self-confidence should improve performance.

\subsubsection{Self-talk}

Besides the other mentioned mental strategies to overcome stress and anxiety, self-talk is one effective technique used by athletes to overcome levels of anxiety (Gholamreza, Aziz \& Jafarzadeh, 2016, as cited in [45]) and to boost self-confidence [46]. Self-talk is a self-regulative technique in which people talk to themselves to control and manage their thougths [47]. 
Moreover, self-talk can be divided into instructional or motivational self-talk. The former refers to focusing one's attention (see the target) whereas the latter encompasses pushing oneself (Let's go) [48]. Several studies indicate self-talk as a technique to enhance performance in the field of sport [e.g. 45, 48].

Due to the results, it can be assumed that this mental technique influences one's attention. This highlights that there is a link between several mental strategies. In the field of firefighters, positive motivational self-talk might be helpful to reduce stress and to focus mainly on the performance.

\subsubsection{Imagery}

The concept of imagery refers to mental strategies and can be defined as a mental simulation of a pre or post-performed tasks by using all senses [49]. In general, imagery is used to prepare oneself for future actions, mostly being used directly before performing an action [49]. Orlick and Partington interviewed an Olympic springboard diver, who illustrates the construct of imagery as followed: 'I did my dives in my head all the time. (...) I started with a front dive, the first one that I had to do at the Olympics, and I did everything as if I was actually there' [8]. This description points out of this imagery refers to a visual and kinesthetic mental simulation. The perspective of imagery can be either internal or external. An external imagery refers to perspective of oneself from the outside and an internal imagery is the imagination of a situation from a person's point of view [49].

Besides in sports psychology, it is also investigated in the field of medicine $[49,50]$. Despite of studies supporting a positive relationship between imagery and performance [e.g. $8,51]$, an increasing amount of studies exists which emphasise imagery additionally as an influencing factor to several constructs, for instance self-confidence [52].

Until today, there is no research available investigating the relationship of imagery and performance in the field of firefighters, but due to the results, one can assume that imagery is relevant to improve performance and would therefore lead to success.

\section{THE PRESENT STUDY}

Until now, mental preparation and mental readiness have not been used to explain performance of firefighters. However, as mentioned above, firefighters are confronted with many high demandings task environments, which in turn might threat task performance and the final success of firefighter operations. One explanation for the performance and success decline is the lack of mental readiness during firefighter's task completion. To obtain a sufficient performance level, the firefighter must have an adequate level of mental readiness to cope with stressful situations (by using relaxation, self-talk and activation strategies), to recognize risks of fire and fast situation changes in good time (by gaining adequate attentional control, visual imagery and warding off distraction), and to accomplish complex psychomotor tasks in dynamic and dangerours environments (by the use of goal setting, attentional processes and self-confidence).

In this study we used a mental readiness measure for firefighters to explain differences in task performance, success and perceived stress.

\section{METHOD}

\subsection{Participants}

Sixty eight firefighters were surveyed regarding their level of mental readiness during their operations as well as the respective task performance, success and stress. 61 valid questionnaires 
were returned. Since not every participant stated his accurate age, only the range of age is given (from 18 to 55 years). All participants were male (mean of years of work experience $=14,48$ years, SD = 10,37). The level of work experience was divided into three parts: Inexperienced: years of service is less than 5 years, experienced: years of service is between 5 and 15 years, and highly experienced: years of service is above 15 years. The sample can be divided into highly experienced (44.3\%), experienced (31.1\%) and inexperienced (24.6\%) firefighters.

\subsection{Materials}

A questionnaire was used that consisted of two parts. Part one comprised the Mental Readiness Scale (MRS) [53] which included 50 Likert-items with a seven-point-scale $(1=$ totally disagree $-7=$ totally agree), specifically designed for mental readiness aspects of firefighters. The MRS encompasses seven sub-scales: goal-setting ( 7 items), attentional control (6 items), relaxation (8 items), activation (3 items), imagery (10 items), self-confidence (8 items) and self-talk ( 8 items) (see Table 1$)$. The second part of the questionnaire contained three criterion

Table 1: Reliability, descriptive statistics and example items of MRS sub-scales.

\begin{tabular}{|c|c|c|c|}
\hline Sub-scale & $\alpha$ & M (SD) & Example items \\
\hline $\begin{array}{l}\text { Attentional } \\
\text { control }\end{array}$ & .73 & $5.45(.68)$ & $\begin{array}{l}\text { - During the operation I was able to } \\
\text { concentrate well. } \\
\text { - During the operation my attention faded (-) }\end{array}$ \\
\hline Imagery & .84 & $4.75(.94)$ & $\begin{array}{l}\text { - Just before the operation, I rehearsed all the } \\
\text { procedural steps in my mind. } \\
\text { - During the operation, I did not think about } \\
\text { the right execution. (-) }\end{array}$ \\
\hline Goal setting & .63 & $4.41(.79)$ & $\begin{array}{l}\text { - My goals were realistic. } \\
\text { - When preparing for the operation, I set } \\
\text { milestones to myself. }\end{array}$ \\
\hline Relaxation & .75 & $3.67(.92)$ & $\begin{array}{l}\text { - I managed to put myself in a relaxed state } \\
\text { during the operation. } \\
\text { - During the operation, I did not use any } \\
\text { relaxation techniques. (-) }\end{array}$ \\
\hline Activation & .80 & $5.15(1.0)$ & $\begin{array}{l}\text { I rarely succeeded in optimally activating } \\
\text { myself when preparing for the mission. (-) } \\
\text { - I managed to increase my energy level to an } \\
\text { optimal level of performance. }\end{array}$ \\
\hline $\begin{array}{l}\text { Self- } \\
\text { confidence }\end{array}$ & .83 & $5.79(.65)$ & $\begin{array}{l}\text { - When I faced some obstacles, I lost faith in } \\
\text { myself. (-) } \\
\text { - I believed in my skills even if something } \\
\text { went wrong during the operation. }\end{array}$ \\
\hline Self-talk & .78 & $3.73(1.0)$ & $\begin{array}{l}\text { - I talked to myself during the operational } \\
\text { preparation. } \\
\text { - As I prepared for the operation, I did not } \\
\text { talk to myself. (-) }\end{array}$ \\
\hline
\end{tabular}

$(-)=$ negatively keyed items 
measures: perceived stress, task performance and success of the operation. Task performance and success of the operation were rated on a seven-point scale $(1=$ very bad $-7=$ very good $)$. Perceived stress (during task preparation and during operation) was rated on a seven-point scale $(1=$ very relaxed $-7=$ highly stressed $)$. The reliabilities of the MRS sub-scales ranged from acceptable (e.g. goal setting $\alpha=.63$ ) to good (e.g. imagery $\alpha=.84$ ).

\subsection{Procedure}

The MRS, questions about demographic data and the criterion measures (perceived stress, task performance, and operational success) were presented via paper-pencil questionnaire at the fire station of the surveyed firefighters. Approximately 15 minutes were needed to complete the entire questionnaire. To ensure a full understanding of the constructs mentioned in the questionnaire, certain terms (e.g. operation, operational preparation, visualisation, relaxation, self-talk, activation) were explained to the respondents at the beginning of the questionnaire.

\section{RESULTS}

\subsection{Mental readiness and perceived stress}

Table 2 summarizes the criterion-validity of the single mental readiness scales for the criterion 'perceived stress'. The regression analysis reveals huge differences between the mental readiness sub-scales. Relaxation, attentional control, and imagery significantly predicted the perceived stress level of the firefighters. Other sub-scales such as self-talk, self-confidence, activation and goal-setting did not significantly contribute to this prediction. However, there is one interesting finding in this prediction: Whereas, an increased use of relaxation and attentional control reduces stress, it seems that an increased use of imagery even increases the perceived stress level of firefighters.

\subsection{Mental readiness and task performance}

Table 3 presents the criterion-validity of the single mental readiness scales for the criterion 'task performance'. Self-confidence was the only mental readiness sub-scale that predicted the task performance of the firefighters.

Table 2: Regression analysis for predicting 'Perceived Stress'.

\begin{tabular}{|c|c|c|c|c|c|}
\hline Variables & $\mathbf{R}$ & $\mathbf{R}^{2}$ & $\mathbf{F}$ & B & $\mathbf{t}(\mathbf{B})$ \\
\hline & 0.77 & 0.59 & $11.05 * * *$ & & \\
\hline Relaxation & & & & -.55 & $-4.96 * * *$ \\
\hline Self-Talk & & & & .16 & 1.43 \\
\hline Self-Confidence & & & & .01 & .08 \\
\hline Activation & & & & -.03 & -.25 \\
\hline Imagery & & & & .33 & $2.85 * *$ \\
\hline Attentional Control & & & & -.40 & $-3.32 * * *$ \\
\hline Goal-Setting & & & & .06 & .54 \\
\hline
\end{tabular}

$\mathrm{N}=61 ;$ Significance level: $* \mathrm{p}<.05 ; * * \mathrm{p}<0.01 ; * * * \mathrm{p}<.001$. 
Table 3: Regression analysis for predicting 'Task Performance'.

\begin{tabular}{|c|c|c|c|c|c|}
\hline Variables & $\mathbf{R}$ & $\mathbf{R}^{2}$ & $\mathbf{F}$ & B & $\mathbf{t}(\boldsymbol{B})$ \\
\hline & 0.68 & 0.46 & $6.33 * * *$ & & \\
\hline Relaxation & & & & .03 & .20 \\
\hline Self-Talk & & & & .13 & .98 \\
\hline Self-Confidence & & & & .66 & $5.12 * * *$ \\
\hline Activation & & & & -.20 & -1.58 \\
\hline Imagery & & & & .06 & .41 \\
\hline Attentional Control & & & & .07 & .49 \\
\hline Goal-Setting & & & & -.03 & -.22 \\
\hline
\end{tabular}

$\mathrm{N}=61$; Significance level: $* \mathrm{p}<.05 ; * * \mathrm{p}<0.01 ; * * * \mathrm{p}<.001$.

Table 4: Regression analysis for predicting 'Success of the Operation'.

\begin{tabular}{lccccc}
\hline Variables & $\mathbf{R}$ & $\mathbf{R}^{\mathbf{2}}$ & $\mathbf{F}$ & $\mathbf{B}$ & $\mathbf{t}(\boldsymbol{\beta})$ \\
& 0.59 & 0.35 & $4.14^{* *}$ & & \\
Relaxation & & & & .00 & .03 \\
Self-Talk & & & -.17 & -1.21 \\
Self-Confidence & & & & .16 & 1.16 \\
Activation & & & .45 & $3.36^{* *}$ \\
Imagery & & & .41 & $2.82^{* *}$ \\
Attentional Control & & & -.17 & -1.21 \\
Goal-Setting & & & & -.11 & -.74 \\
\hline
\end{tabular}

$\mathrm{N}=61$; Significance level: $* \mathrm{p}<.05 ; * * \mathrm{p}<0.01 ; * * * \mathrm{p}<.001$.

\subsection{Mental readiness and success of the operation}

The criterion-validity of the single mental readiness scales for the criterion 'success of the operation' is summarized in Table 4 . Activation and imagery were the only mental readiness sub-scales that predicted the firefighters' success of their operation.

\section{DISCUSSION}

\subsection{Interpretation of results}

As has been shown in Tables 1-4, the study produced mixed results. The mean values of the MRS sub-scales (see Table 1), ranged between medium (e.g. relaxation: $M=3.67$ ) and large (e.g. self-confidence: $M=5.79$ ). In addition, it seems that not all mental readiness dimensions equally contribute to stress reduction, task performance and success of firefighters' operations. In respect of stress reduction, relaxation techniques and attentional control can obviously lower the perceived stress level of firefighters. Furthermore, scales like imagery are positively correlated with stress. Probably, to rehearse procedural steps and anticipate problems in one's mind seems to demand cognitive resources, which are urgently needed for the firefighters' task. Therefore, the visual imagery seems to overload the cognitive capacity of 
firefighters. Acceding to the task performance criterion, only the self-confidence sub-scale seems to be relevant. Finally, activation and imagery contributed significantly to the prediction of the success of firefighters' operations. Hence, in particular the visual imagery dimension seems to be a mixed blessing phenomenon, which should be investigated more thoroughly in the near future. Whereas visual imagery increases stress, it has a positive impact on the final success of firefighters' operations even thought it does not affect the firefighters' task performance. Other mental readiness dimensions such as goal-setting and self-talk might not be relevant for firefighters task performance and stress remediation.

\subsection{Strengths and Limitations}

The current study has both strengths and limitations. One advantage is the novelty of applying a human performance construct from sports psychology to the field of firefighters. As mentioned above, mental readiness has been used to explain variations in peak performance of athletes but never in the field of firefighters' performance. With respect to three regression analyses, there is empirical evidence that specific mental readiness dimensions are relevant in the task context of firefighters. In addition, the reliability of most scales was good. The internal consistency ranged between Cronbach's $\alpha=.63-.84$.

Beside these strengths, there are also some noteworthy limitations. First, all criterion measures were only proxy-measures in the firefighters' task context. In this survey there was no opportunity to assess the real task performance and to collect operational safety-critical success parameters such as saved lives, destroyed buildings or delayed arrivals at the operational site. Furthermore, the internal consistency of the goal-setting scale should be improved. Finally, the sample size was rather small.

\section{CONCLUSION}

The present study has several implications for future safety research and practice. Specifically, this study was the first attempt to transfer a psychological concept aimed to increase human performance in the sport sector to the task context of firefighters. It was shown that mental readiness dimensions have an effect on task performance, perceived stress and operational success of firefighters. Future research should focus on the relation of visual imagery and task performance as well as stress indicators. A promising research strategy might be to measure the level of visual imagery and to test the task performance and stress effects in firefighter simulator experiments by recording safety-relevant indicators (e.g. near accidents, risky rescuing manoeuvres, delayed reactions, recognition of sudden situation changes). Additional measures such as eye-tracking and reaction time data could be used to validate the imagery sub-scale. This could be a useful step to develop mental trainings, which support firefighters to execute their actions more effectively. Another, relevant aspect to be further investigated might be the relation between mental preparation and job experience. Hence, future mental training concepts could be specifically designed for the different needs of inexperienced and experienced firefighters.

Furthermore, future studies should focus on effects of attentional control, self-confidence and relaxation on performance under stress. Therefore, trainings should be offered to practice how to relax and keep the task focus in stressful situations. Besides those mental trainings, firefighters should also be involved in high-fidelity firefighter simulations to train situations as realistic as possible on a regular basis, which might boost one's self-confidence as well. Besides physical fidelity, training principles with psychological fidelity will help to learn how to deal with stress and to control distractions. Moreover, it is of importance that firefighters 
gain an optimal arousal level to perform successfully. This can be established by teaching mental preparation strategies. Additionally, it should be taken into account that the performance of firefighters depends on the whole team. Thus, it is highly relevant that teams engage in team reflections and proactive communication, especially by practicing closed-loop communication, to maintain a shared situation awareness [54, 55]. Finally, this research strategy could also be transferred to other safety-critical industries such as aviation, medicine or nuclear power plants where mental preparation strategies and mental readiness might be important too.

\section{REFERENCES}

[1] Bos, J., Mol, E., Visser, B. \& Frings-Dresen, M.H., The physical demands upon (Dutch) firefighters in relation to the maximum acceptable energetic workload. Ergonomics, 47(4), pp. 446-460, 2004. https://doi.org/10.1080/00140130310001643283

[2] Guidotti, T.L., Human factors in firefighting: ergonomic-, cardiopulmonary-, and psychogenic stress-related issues. International Occupational Environmental Health, 64(1), pp. 1-12, 1992. https://doi.org/10.1007/bf00625945

[3] Perroni, F., Cignitti, L., Cortis, C. \& Capranica, L., Physical fitness profile of professional Italian firefighters: Differences among age groups. Applied Ergonomics, 45(3), pp. 456-461, 2014. https://doi.org/10.1016/j.apergo.2013.06.005

[4] Smith, D.L., Firefighter fitness: Improving performance and preventing injuries and fatalities. Current Sports Medicine Reports, 10(3), pp. 167-172, 2011. https://doi. org/10.1249/jsr.0b013e31821a9fec

[5] Karter, Jr., M.J. \& Molis, J.L., U.S. Firefighter Injuries - 2010, National Fire Protection Association: Quincy, MA., 2011.

[6] Driskell, J.E., Copper, C. \& Moran, A., Does mental practice enhance performance? Journal of Applied Psychology, 79(4), pp. 481-492, 1994. https://doi.org/10.1037//00219010.79.4.481

[7] Gould, D., Flett, M.R. \& Bean, E., Mental preparation for training and competition (Chapter 6). Handbook of Sports Medicine and Science. Sport psychology, ed. B.W. Brewer, Wiley-Blackwell, pp. 53-63, 2009.

[8] Orlick, T. \& Partington, J., Mental links to excellence. The Sport Psychologist, 2(2), pp. 105-130, 1988. https://doi.org/10.1123/tsp.2.2.105

[9] Orlick, T., In pursuit of Excellence. How to wWin in Sport and Life through Mental Training, Human Kinetics: Champaign, 2000.

[10] Baddeley, A.D., Baddeley, H.A., Bucks, R.S. \& Wilcock, G.K., Attentional control in Alzheimer's disease. Brain, 124(8), pp. 1492-1508, 2001. https://doi.org/10.1093/ brain/124.8.1492

[11] Bell, J.J. \& Hardy, J., Effects of attentional focus on skilled performance in golf. Journal of Applied Sport Psychology, 21(2), pp. 163-177, 2009. https://doi. org/10.1080/10413200902795323

[12] Wulf, G. \& Su, J., An external focus of attention enhances golf shot accuracy in beginners and experts. Research Quarterly for Exercise and Sport, 78(4), pp. 384-389, 2007. https://doi.org/10.1080/02701367.2007.10599436

[13] Stoate, I. \& Wulf, G., Does the attentional focus adopted by swimmers affect their performance? International Journal of Sports Science, 6(1), pp. 99-108, 2011. https:// doi.org/10.1260/1747-9541.6.1.99

[14] Duke, R.A., Cash, C.D. \& Allen, S.E., Focus of attention affects performance of motor skills in music. Journal of Research in Music Education, 59(1), pp. 1-12, 2011. https:// doi.org/10.1177/0022429410396093 
[15] Talbot-Honeck, C. \& Orlick, T., The essence of excellence: mental skills of top classical musicians. Journal of Excellence, 1, pp. 61-75, 1998.

[16] Rossettini, G., Testa, M., Vicentini, M. \& Manganotti, P., The effect of different attentional focus instructions during finger movement tasks in healthy subjects: An exploratory study. BioMedResearch International,2017,pp. 1-8, 2017.https://doi.org/10.1155/2017/2946465

[17] Diekfuss, J.A., Janssen, J.A., Slutsky, A.B., Berry, N.T., Etnier, J.L., Wideman, L. \& Raisbeck, L.D., An external focus of attention is effective for balance control when sleep-deprived. International Journal of Exercise Science, 11, pp. 84-94, 2018.

[18] McDonald, J., Orlick, T. \& Letts, M., Mental readiness in surgeons and its links to performance excellence in Surgery. Journal of Pediatric Orthopaedics, 15(5), pp. 691-697, 1995. https://doi.org/10.1097/01241398-199509000-00027

[19] Darowski, E.S., Helder, E., Zacks, R.T., Hasher, L. \& Hambrick, D.Z., Age-related differences in cogntion: The role of distraction control. Neuropsychology, 22(5), pp. 638-644, 2008. https://doi.org/10.1037/0894-4105.22.5.638

[20] Gould, D., Greenleaf, C., Guinan, D., Dieffenbach, K. \& McCann, S., Pursuing performance excellence: Lessons learned from olympic athletes and coaches. Journal of Excellence, 4, pp. 21-43, 2001.

[21] Church, H.R., Rumbold, J.L. \& Sandars, J., Applying sport psychology to improve clinical performance. Medical Teacher, 39(12), pp. 1205-1213, 2017. https://doi.org/1 0.1080/0142159x.2017.1359523

[22] Locke, E.A. \& Latham, G. P., A Theory of Goal Setting \& Task Performance, PrenticeHall, Inc: Englewood Cliffs, NJ, US, 1990.

[23] Locke, E.A. \& Latham G.P., Goalsetting Theory, 1990 (Chapter 1), New Developments in Goalsetting and Task Performance, eds. E.A. Locke \& G.P.Latham, Routledge: New York, pp. 3-15, 2013.

[24] Landers, R.N., Bauer, K.N., \& Callan, R.C., Gamification of task performance with leaderboards: A goal setting experiment. Computers in Human Behavior, 71, pp. 508-515, 2017. https://doi.org/10.1016/j.chb.2015.08.008

[25] Van Lent, M. \& Souverijn, M., Goal setting and raising the bar: A field experiment. Tinbergen Institute Discussion Paper 17-001/VII, pp. 1-54, 2017.

[26] Vaez-Mousavi, S.M., Hashemi-Masoumi, E. \& Jalali, S., Arousal and activation in a sport shooting task. World Applied Sciences Journal, 4, pp. 824-829, 2008.

[27] Barry, R.J., Clarke, A.R., McCarthy, R., Selikowitz, M. \& Rushby, J.A., Arousal and activation in a continuous performance task: An exploration of state effects in normal children. Journal of Psychophysiology, 19(2), pp. 91-99, 2005. https://doi. org/10.1027/0269-8803.19.2.91

[28] Hebb, D.O., Drives and the CNS. Psychological Review, 62(4), pp. 243-254, 1955. https://doi.org/10.1037/h0041823

[29] Hammoudi-Nassib, S., Nassib, S., Chtara, M., Briki, W., Chaouachi, A., Tod, D. \& Chamari, K., Effects of psyching-up on sprint performance. Journal of Strength and Conditioning Research, 31(8), pp. 2066-2074, 2017. https://doi.org/10.1519/jsc.0000000000000373

[30] Gould, D., Weinberg, R.S. \& Jackson, A.S., Mental preparation strategies, cognitions and strength performance. Journal of Sport Psychology, 2(4), pp. 329-339, 1980. https://doi.org/10.1123/jsp.2.4.329

[31] Tynes, L.L. \& McFatter, R.M., The efficacy of "Psyching" strategies on a weightlifting task. Cognitive Therapy and Research, 11(3), pp. 327-336, 1987. https://doi. org/10.1007/bf01186283 
[32] Zaichkowsky, L.D. \& Baltzell, A., Arousal and performance. In Handbook of Sport Psychology, eds. R.N. Singer, H.A. Hausenblas \& C.M. Janelle, 2nd edn, pp. 319-339. Wiley \& Sons: New York, 2001.

[33] Crocker, P.R.E. \& Graham, T.R., Coping by competitive athletes with stress: Gender differences and relationships with affect. The Sport Pschologist, 9(3), pp. 325-336, 1995. https://doi.org/10.1123/tsp.9.3.325

[34] Hardy, L., Jones, G. \& Gould, D., Understanding Psychological Preparation for Sport: Theory and Practice of Elite Performers. Wiley: Chichester, UK, 1996.

[35] Kudlackova, K., Eccles, D.W. \& Dieenbach, K., Use of relaxation skills in differentially skilled athletes. Psychology of Sport and Exercise, 14(4), pp. 468-475, 2013. https:// doi.org/10.1016/j.psychsport.2013.01.007

[36] Shen, X., Zhu, X., Wu, Y., Zhou, Y., Yang, L., Wang, Y., Zheng, Q., Liu, Y., Cong, S., Xiao, N. \& Zhao, Q., Effects of a psychological intervention programme on mental stress, coping style and immune function in percutaneous coronary intervention patients. PLoS ONE, 13(1), p. e0187745, 2018. https://doi.org/10.1371/journal. pone. 0187745

[37] Thelwell, R.C. \& Greenlees, I.A., Developing competitive endurance performance using mental skills training. The Sport Psychologist, 17(3), pp. 318-337, 2003. https:// doi.org/10.1123/tsp.17.3.318

[38] Poulin, P.A, Mackenzie, C.S., Soloway, G. \& Karayolas, E., Mindfulness training as an evidenced-based approach to reducing stress and promoting well-being among human services professionals. International Journal of Health Promotion \& Education, 46(2), pp. 35-43, 2008. https://doi.org/10.1080/14635240.2008.10708132

[39] Feltz, D., Self-confidence and sports performance. Exercise and Sport Sciences Reviews, 16, pp. 423-458, 1988. https://doi.org/10.1249/00003677-198800160-00016

[40] Bandura, A., Social foundations of thought and action. A Social Cognitive Theory. Prentice-Hall: Englewood Cliffs, NJ, 1986.

[41] Woodman, T. \& Hardy, L., The relative impact of cognitive anxiety and self-confidence upon sport performance: A meta-analysis. Journal of Sport Sciences, 21(6), pp. 443-457, 2003. https://doi.org/10.1080/0264041031000101809

[42] Gould, D., Petlichkoff, L., Simons, J. \& Vevera, M., Relationship between competitive state anxiety inventory-2-subscale scores and pistol shooting performance. Human Kinetics Journals, 9(1), pp. 33-42, 1987. https://doi.org/10.1123/jsp.9.1.33

[43] Woodman, T., Akehurst, S., Hardy, L. \& Beattie, S., Self-confidence and performance: A little self-doubt helps. Psychology of Sport and Exercise, 11(6), pp. 467-470, 2010. https://doi.org/10.1016/j.psychsport.2010.05.009

[44] Campbell, W.K., Goodie, A.S. \& Foster, J.D., Narcissism, confidence and risk attitude. Journal of Behavioral Decision Making, 17(4), pp. 297-311, 2004. https://doi. org/10.1002/bdm.475

[45] Dali, M.S. \& Parnabas, V.A., The effects of self-talk on free throw performance and the level of anxiety among male novice basketball players. Movement, Health \& Exercise, 7(1), pp. 73-87, 2018. https://doi.org/10.15282/mohe.v7i1.174

[46] Vealey, R.S., Understanding and enhancing self-confidence in athletes, Handbook of Sport Psychology, eds. G. Tenenbaum \& R. Eklund, 2nd ed., Wiley \& Sons: New York, pp. 550-565, 2001.

[47] Bull, S.J., Albinson, J.G. \& Shambrook, C.J., The mental game plan: getting psyched for sport. Sports Dynamics: Eastbourne, 1996. 
[48] Hatzigeorgiadis, A., Zourbanos, N., Galanis, E. \& Theodorakis, Y., Self-talk and sport performance: A meta-analysis. Perspectives on Psychological Science, 6(4), pp. 348-356, 2011. https://doi.org/10.1177/1745691611413136

[49] Weinberg, R., Does imagery work? effects on performance and mental skills. Journal of Imagery Research in Sport and Physical Activity, 3(1), pp. 1-21, 2008. https://doi. org/10.2202/1932-0191.1025

[50] Patel, S.R., Gohel, M.S., Hamady, M., Albayati, M.A., Riga, C.V., Cheshire, N.J.W. \& Bicknell, C.D., Reducing errors in combined open/endovascular arterial procedures: Influence of a structured mental rehearsal before the endovascular phase. Journal of Endovascular Therapy, 19(3), pp. 383-389, 2012. https://doi.org/10.1583/11-3785r.1

[51] Holmes, E.A., Mathews, A., Dalgleish, T. \& Mackintosch, B., Positive interpretation training: Effects of mental imagery versus verbal training on positive mood. Behavior Therapy, 37(3), pp. 237-247, 2006. https://doi.org/10.1016/j.beth.2006.02.002

[52] Mamassis, G. \& Doganis, G., The effects of a mental training on juniors pre-competitive anxiety, self-confidence, and tennis performance. Journal of Applied Sport Psychology, 16(2), pp. 118-137, 2004. https://doi.org/10.1080/10413200490437903

[53] Marquardt, N., Hannig, C. \& Hannig, S., Mental readiness and performance under stress. International Journal of Psychology, 51, pp. 766-766, 2016.

[54] Jouanne, E., Charron, C., Chauvin, C. \& Morel, G., Correlates of team effectiveness: An exploratory study of firefighter's operations during emergency situations. Applied Ergonomics, 61, pp. 69-77, 2017. https://doi.org/10.1016/j.apergo.2017.01.005

[55] Marquardt, N., Situation awareness, human error, and organizational learning in sociotechnical systems. Human Factors and Ergonomics in Manufacturing \& Service Industries, 29, 327-339, 2019. https://doi.org/10.1002/hfm.20790 